\title{
Leading Edge serrations for the reduction of aerofoil separation self-noise
}

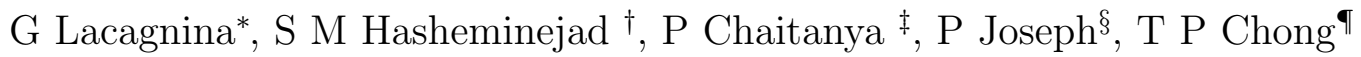 \\ O Stalnov
}

\begin{abstract}
This paper presents an experimental investigation into the use of LE serrations for the reduction of trailing edge self-noise, at least for the NACA-65 aerofoil family. It is shown that the leading edge serrations are able to reduce the self-noise in a low frequency range at small and negative angles of attack. The exact mechanism of this reduction is still not completely discovered, but the LE serrations are discovered able to modulate the mean velocity field and turbulent velocity spectrum in that range of frequencies, as well as to dampen the effect of the angle of attack on the pressure field and to reduce its coherence. We emphasise that this paper represents work in progress and further investigations are still necessary in order to completely understand the dynamics behind this reduction.
\end{abstract}

\section{Introduction}

In the EC Environment Action Programme to 2020 "Living well, within the limits of our planet", is included a commitment to significantly reduce by 2020 the noise pollution into the European Union, towards the levels recommended by the WHO (World Health Organization). One of the main sources of environmental noise is due to aircrafts, exposing almost 3 million people to noise levels above $55 \mathrm{~dB}$ Lden (equivalent continuous noise level over a whole 24-hour period, weighted to reflect the different noise sensitivity over the day). Besides that, many complaints have been made by residents living in the neighbourhood of wind farms that they can cause too much noise. This leads to limitation to the operational conditions of such systems, having significant implications for the growth of the aerospace and renewable energy sectors. Wind turbines and aircrafts have common noise generation mechanisms, namely the interaction between the blades or wings with a turbulent flow around them. A variety of control techniques to reduce aerofoil noise has been proposed so far. They can be classified roughly in active and passive methods. Active flow control, such as wall suction, ${ }^{1}$ aims to reduce TE noise by decreasing the boundary layer thickness at TE, while other active controls, such as flow blowing flap, ${ }^{2}$ by weakening the vortex system and pushing it away from the surface. Recently plasma actuators ${ }^{3}$ are being tested due to their high energy efficiency, fast response and a simple structure, achieving good vortex shedding tonal noise reductions.

Passive methods include serrated edges, ${ }^{4-6}$ porous surfaces ${ }^{7}$ and brushes. ${ }^{8,9}$ All these methods have been tested experimentally in low Reynolds number flow conditions, delivering a noise reduction between 3 and $7 \mathrm{~dB}$. Among all of them, one the most promising seems to be the introduction of serrations on the aerofoil edges. Leading edge (LE) serrations are generally assumed effective in reducing the interaction noise, related to turbulent disturbances convected into the flow which are distorted around the leading edge of the surface, while Trailing edge (TE) serrations act on the self-noise which is due to the interaction between an aerofoil blade and the turbulence produced in its own boundary layer and near wake. In this work the attention is focused on the NACA-65 aerofoil family. The 65-Series are high-performance aerofoils designed to maintain laminar flow over a significant portion of their surface. This type of airfoil was used on high-performance fighter aircrafts built during World War II and then has been widely tested by NACA for

\footnotetext{
*Research fellow, University of Southampton, SO17 1BJ Southampton, UK; G.Lacagnina@soton.ac.uk

${ }^{\dagger}$ Research fellow, Brunel University London, UB8 3PH Uxbridge, UK; m.Hasheminejad@brunel.ac.uk

${ }^{\ddagger}$ PhD student, University of Southampton, SO17 1BJ Southampton, UK; ccp1u12@soton.ac.uk

§Professor, University of Southampton, SO17 1BJ Southampton, UK, Senior member AIAA; pfj@soton.ac.uk

『Senior Lecturer, , Brunel University London, UB8 3PH Uxbridge, UK, AIAA member; T.P.Chong@brunel.ac.uk

" Assistant Professor, Technion-Israel Institute of Technology, 32000 Haifa, Israel, AIAA member; oksana.s@technion.ac.il
} 
cascades and are used in most commercial axial-flow compressors in gas turbines built before the 90s. Recent investigations on Leading Edge serrations ${ }^{10}$ installed on NACA-65 aerofoils have highlighted that they are able to reduce also the self-noise in addition to the interaction one. This paper aims to shed light on this new feature, investigating the modifications induced by the leading edge serration to the aerofoil boundary layer, principally around the trailing edge where the self-noise originates and spreads out.

\section{A. Separation noise}

According to Brooks et al, ${ }^{12}$ at least five self-noise mechanisms can be identified. The most common source, which has been extensively investigated in the past, is the Turbulent-Boundary-Layer-Trailing-Edge Noise, where a turbulent boundary layer develops over most of the airfoil and then noise is produced as this turbulence passes over the trailing edge (TE). The current paper aims to investigate also an additional source, which has been assessed to a very limited extent until now, the separated flow noise mechanism, where the flow separates along the chord of the aerofoil to produce TE noise due to the shed turbulent vorticity. To this aim a NACA-65 aerofoil has been chosen, due to the existence of a separation bubble on its pressure side, which is supposed to generate separation noise in order to investigate strategies to reduce the selfnoise from this source.

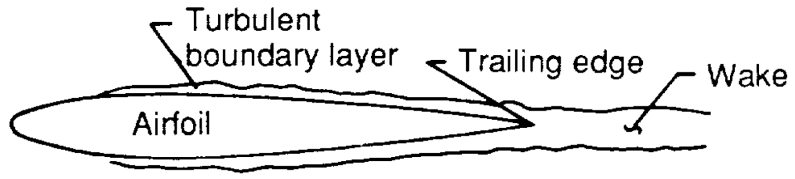

Turbulent-boundary-layer-trailing-edge noise

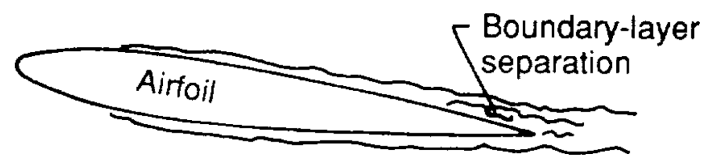

Separation-noise

Figure 1: Turbulent boundary layer and boundary layer separation TE noise after Brooks ${ }^{12}$

\section{Aerofoil configurations}

The effect of Leading Edge serration is investigated on the noise of NACA65(12)10 aerofoil. The parameters describing the serrations are the wavelength $\lambda$ and the height $h$. A wide serration $(\lambda=30 \mathrm{~mm} ; h=$ $22.5 \mathrm{~mm}$ ) has been chosen as a reference for most of the measurements, unless otherwise stated. Moreover seven different geometrical angles of attack have been investigated, namely $+9,+5,+2,0,-2,-5$ and -9 . The interest in this study is focused on the self-noise due to separating turbulent flow and to avoid the tonal noise generation due to Tollmien - Schlichting instabilities in a laminar condition, the flow near the leading edge is tripped to obtain turbulent conditions by means of a band of rough paper at a location of around $\frac{x}{c}=0.366$ on both the pressure and the suction sides.

First of all the reference system in figure 2 , such that $\mathrm{X}=0$ is the trailing edge, $\mathrm{X}=1$ is the leading edge and $\mathrm{r}$ is the spanwise coordinate, is defined. Introducing the mean chord $C_{0}$, the chord length close to the LE varies according to $c(r)=C_{0}+h \sin (2 \pi r / \lambda)$, ensuring that the wetted area remains constant between serrated and unserrated aerofoils. Then, the profile $\mathrm{y}(\mathrm{X}, \mathrm{r})$ at any position $\mathrm{r}$ along the aerofoil can be described as

$$
y(X, r)=\left\{\begin{array}{lr}
f\left(x / C_{0}\right) & 0<x / C_{0}<2 / 3 \\
f(x / c(r)) & 2 / 3<x / c(r)<1
\end{array}\right.
$$

A preliminary analisys by means of the XFoil program has highlighted the existence of a small recirculation bubble on the pressure side of the aerofoil, close to the TE, as is shown in figure 3 (Left), where the thickness of the boundary layer on both sides of the aerofoil is depicted.

The existence of this recirculation bubble had already been pointed out by Gruber in his $\mathrm{PhD}$ thesis in 2012. ${ }^{11}$ This separation bubble and the suppression of it by the introduction of the Leading Edge serrations could be one of the sources of reduction of the selfnoise, which therefore can be accounted also as boundary layer separation noise, as described by Brooks, ${ }^{12}$ in addition to the standard turbulent-boundarylayer trailing-edge selfnoise, see figure 1. 


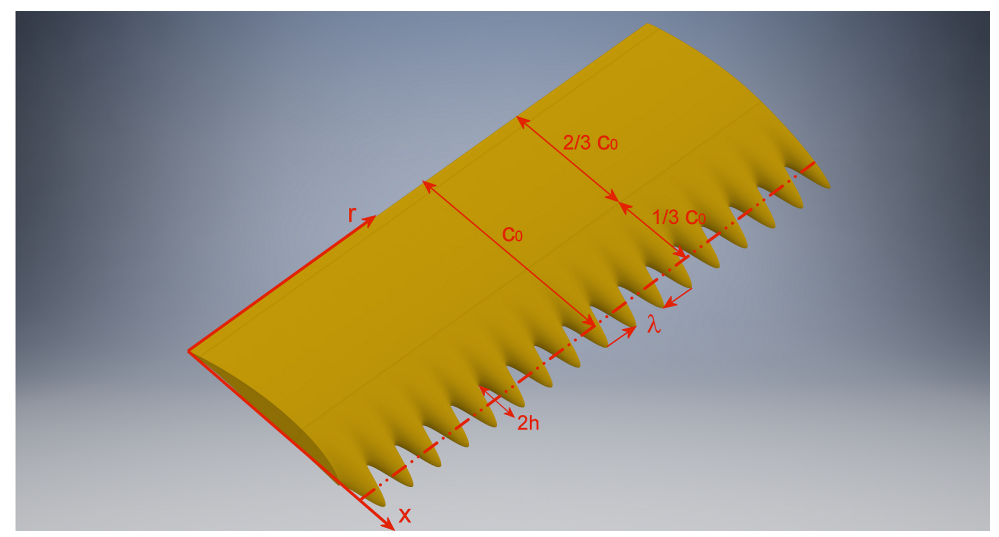

Figure 2: A sketch of the LE serrated aerofoil displaying its parameters
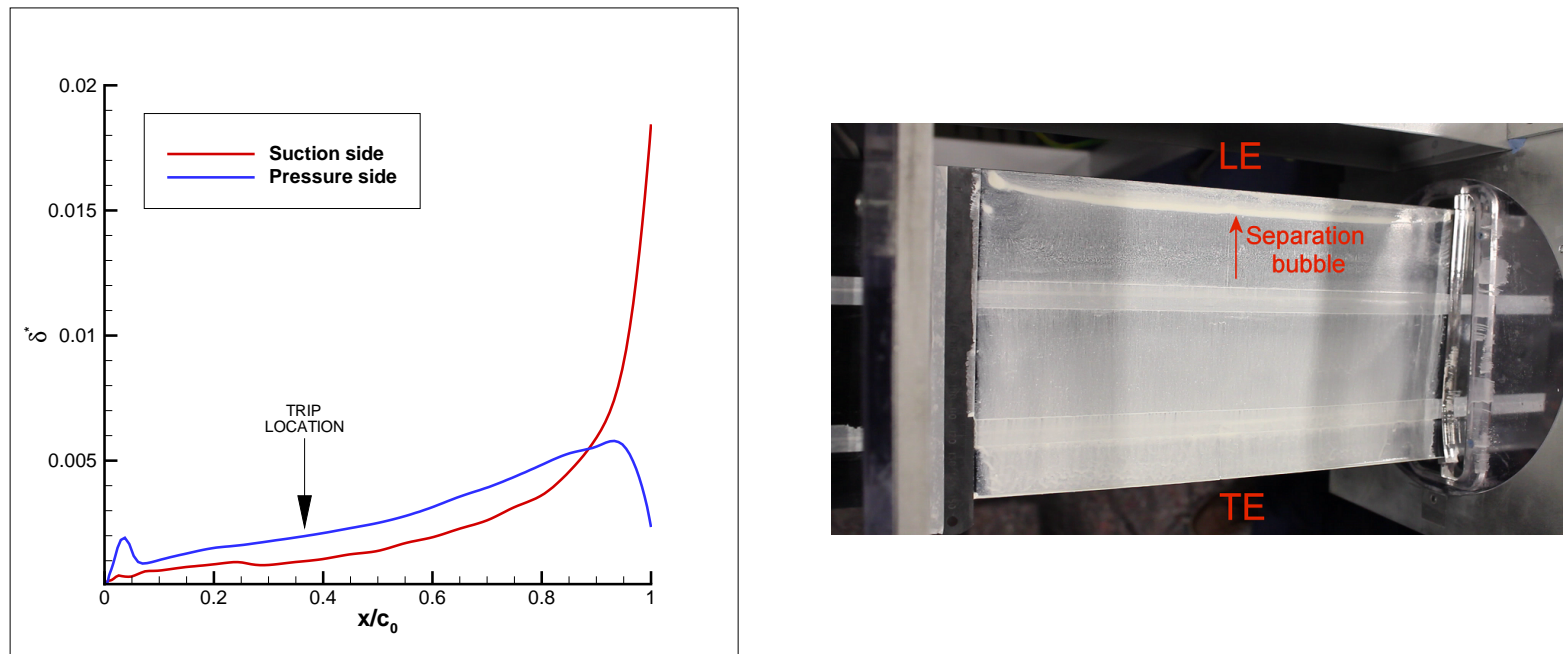

Figure 3: Boundary layer thickness at $0 \mathrm{deg}$ AoA and $40 \mathrm{~m} / \mathrm{s}$ estimated by XFoil, LE separation (Left); Oil visualization of the separation bubble on the pressure side of the aerofoil at 0 deg AoA and $20 \mathrm{~m} / \mathrm{s}$ (Right);

\section{Experimental Setup}

\section{A. Noise measurement}

Acoustic measurements of the self-noise have been carried on in the open jet wind tunnel facility of ISVR, in Southampton (figure 4). It is housed in an anechoic chamber of dimensions $8 \mathrm{~m} \times 8 \mathrm{~m} \times 8 \mathrm{~m}$, whose walls are acoustically treated with glass wool wedges to reach the lowest cut-off frequency of $80 \mathrm{~Hz}$. The flow in the wind tunnel is generated by a centrifugal fan, located over the ceiling of the chamber and driven by a variable speed $110 \mathrm{~kW}$ motor. The air then passes firstly through a series of silencers, to establish a quiet, uniform and low-turbulence flow, and finally through a nozzle of area ratio 25:1 to minimise lateral velocity fluctuations. The nozzle exit has dimensions $0.15 \mathrm{~m}$ and $0.45 \mathrm{~m}$ and to that two side plates are attached to sustain in the flow the aerofoil, which is located $0.15 \mathrm{~m}$ downstream the nozzle, and maintain the flow two-dimensional. For a detailed description of the facility, please make reference to the paper by Chong et al. ${ }^{13}$ An array of 16 half-inch condenser microphones ( $B \& K$ type 4189 ), located at a distance of $1.2 \mathrm{~m}$ at the mid span of the aerofoil, delivered the free-field noise measurements. The emission angles of the microphones, relative to the downstream direction of the jet axis, were in the range of 40 to 130 degrees. Finally, each noise measurement had a duration of $10 \mathrm{~s}$ at the sampling frequency of $50 \mathrm{kHz}$. 


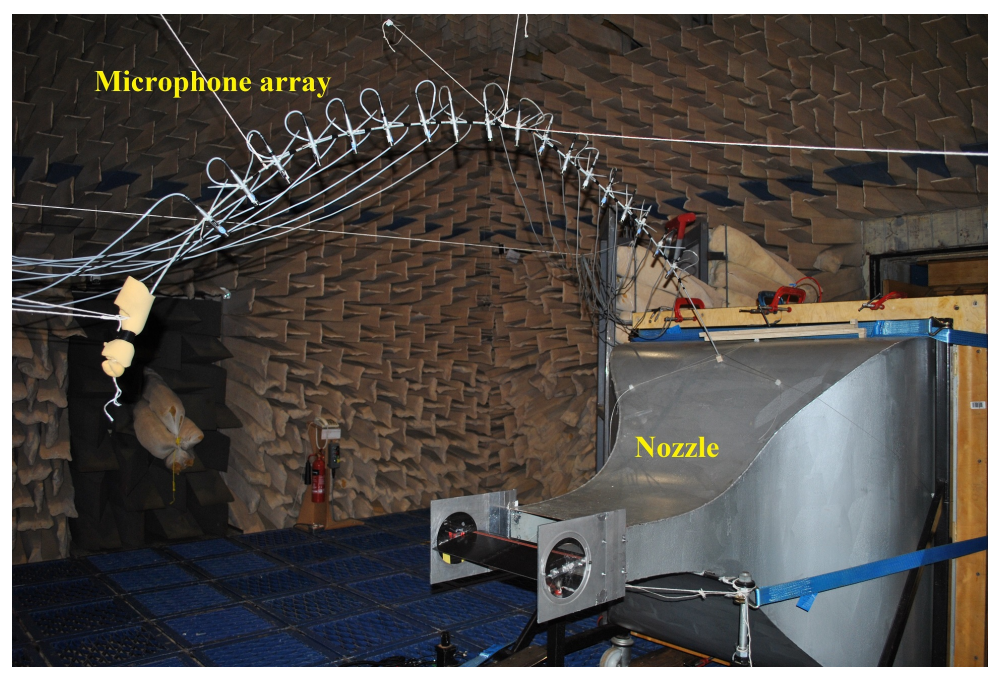

Figure 4: Photograph of jet nozzle and measurement setup inside the ISVRs anechoic chamber

\section{B. Unsteady velocity measurements}

In order to assess the effect exerted by the Leading Edge serrations on the self-noise it is necessary to investigate the modifications induced on the boundary layer as the flow is convected past the Trailing Edge. To do so, hot wire anemometry measurements have been performed using a single hot-wire probe (Dantec type 55P11), driven using a standard constant temperature anemometry bridge (AA Lab System) operated at an over-heat ratio of 1.5. The probe is calibrated in the freestream of the wind tunnel using a Pitot-static tube in a velocity range up to $50 \mathrm{~m} / \mathrm{s}$, fitting the data points on a 4th-order degree polynomial to obtain the calibration curve. To achieve a good statistical convergence, the acquisition time has been set to $20 \mathrm{~s}$ at a data rate of $20 \mathrm{kHz}$.

\section{Unsteady pressure on aerofoil surface}

The investigation on the modifications induced on the boundary layer at the TE by serrations at the LE can be completed by unsteady pressure fluctuations measurements using pressure taps on aerofoil surface. The aerofoil has been accordingly instrumented with inner tubes running below the surface and originating at the pressure taps at TE. To the far end of this tubes a T-junction is connected, in which miniature microphones are installed. These $2.5 \mathrm{~mm}$ diameter omnidirectional electret condenser microphones (Knowles Electronics FG-3329-P07) are responsible for the measurement of the pressure fluctuations. The other end of the Tjunction is connected to a long (about $3 \mathrm{~m}$ ) tube, sealed at the end to avoid reflections. To avoid erroneous measurements, special care needs to be devoted to the sealing. Moreover, the microphones need to be individually calibrated. The calibration against a reference B\&K $\frac{1}{2}$ inch condenser microphone is performed in-situ by means of an in-duct loudspeaker as shown in figure 5

\section{Amiet Theory}

The role of the Trailing Edge in the noise emission is to scatter hydrodynamic pressure fluctuations of relatively short wavelength $\frac{U}{f}$, which lie beneath the turbulent boundary layer and do not radiate to the far field, into much longer wavelength $\left(\frac{c_{0}}{f}\right)$ acoustic waves. Therefore, the surface pressure field at the TE plays the role of the source of the emitted sound. Amiet ${ }^{14}$ in 1976 has proposed a theoretical formulation to link the radiated far-field power spectral density of the acoustic pressure $S_{p p}\left(x_{1}, x_{2}, x_{3}=0, \omega\right)$ to the near-field wall pressure wavenumber-frequency spectral density $S_{q q}(\omega)$ in proximity of TE. For a stationary aerofoil the general expression of $S_{p p}$ at frequency $\omega$ can be written as:

$$
S_{p p}\left(x_{1}, x_{2}, x_{3}, \omega\right) \propto \mathscr{L}(\omega) S_{q q}(\omega)
$$




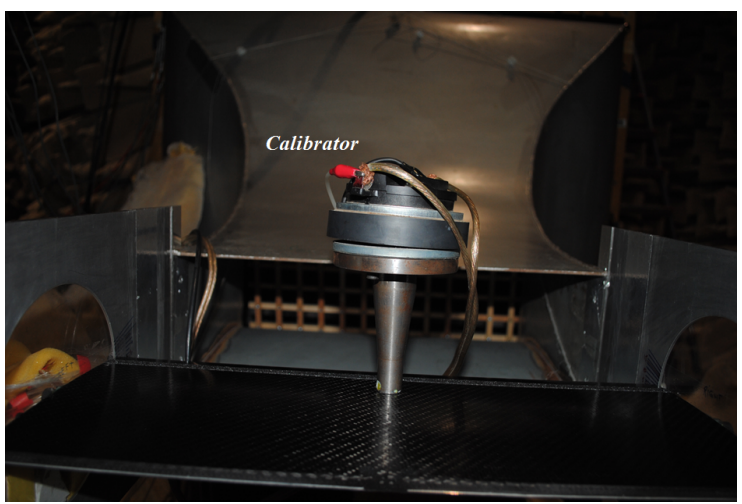

(a) In-situ microphone calibration.

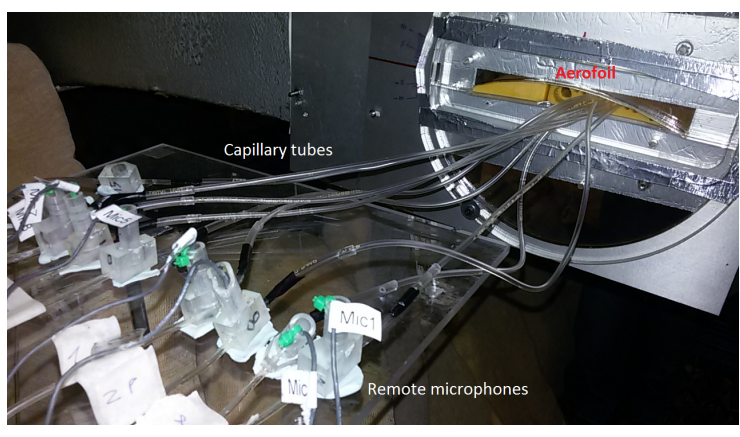

(b) Remote microphone setup to measure surface pressure on the airfoil.

Figure 5: Surface Pressure measurement setup.

Equation 1 will be used in section $\mathrm{F}$ in order to demonstrate that noise reductions in the far field are due to a corresponding reduction in the TE surface pressure and are therefore a form of self noise.

\section{Results and discussion}

\section{A. Acoustic measurements}

As mentioned before, the aim of this work is investigating the effect of leading edge serrations in reducing the self-noise generated at the trailing edge. To do so, acoustic measurements have been first of all performed, in order to assess the different noise emitted by a baseline and a leading edge serrated aerofoil, having as serration parameters $\mathrm{h}=22.5 \mathrm{~mm}$ and $\lambda=30 \mathrm{~mm}$. In figure 6 the self-noise sound power levels emitted by the two different aerofoils at 0 degrees angle of attack, setting the velocity as equal to $20 \mathrm{~m} / \mathrm{s}, 40 \mathrm{~m} / \mathrm{s}$ and $60 \mathrm{~m} / \mathrm{s}$, are plotted.

In order to highlight and quantify the effect of the leading edge serration, the Sound Power Reductions $(\triangle P W L)$ at different velocities are plotted in figure 7 (Left).

The self-noise reduction due to the Leading Edge serrations levels between 5 and $8 \mathrm{~dB}$ at 0 degrees and the maxima perfectly collapse when scaled against a Strouhal number based on a generic lengthscale $\mathrm{L}=1 \mathrm{~m}$. At $40 \mathrm{~m} / \mathrm{s}$ the range of frequency corresponds to about $(200-2000) \mathrm{Hz}$. The effect of the angle of attack is depicted in figure 7 (Right). Negligible noise reduction can be observed at high positive angles of attack, while they become noticeable around 0 degrees AoA condition and remarkable at negative angles. Moreover the highest is the negative angle, in absolute value, the smaller is the frequency at which the maximum noise reductions occur.

\section{B. Unsteady velocity measurements}

Since the self-noise is related to the disturbances of the flow field in the boundary layer which are scattered as they reach the Trailing Edge, the next step has been the measurement of the velocity field at 0 degrees geometrical AoA in the near wake of the aerofoil (1 mm downstream of the TE) making use of the Hot Wire Anemometry. Firstly, the spanwise direction has been scanned along 3 serration wavelengths $(3 \times 3 \mathrm{~cm})$, at 90 positions with a spacing of $1 \mathrm{~mm}$, both at the suction and pressure sides.

In figure 8 the mean streamwise velocity component is depicted on both the suction (a) and presuure (b) sides of the aerofoil. The Leading Edge serrations can be seen generate on the pressure side of the aerofoil a modulation of the velocity fields which resembles the profile of the serrations, retaining a similar wavelength, while the suction side is less affected, showing a near constant trend.

The modulation on the pressure side is a proof that the LE serrations are influencing the flow field at the TE. This modulation can be recovered also in the velocity spectra, as shown in figure 9.

Normalizing the Power Spectral Density of the serrated aerofoil by the corresponding one of the baseline, it is evident how the suction side is influenced to a small extent by the introduction of the serrations while the pressure side exhibits a significant reduction in the same range of frequencies where the noise reduction 


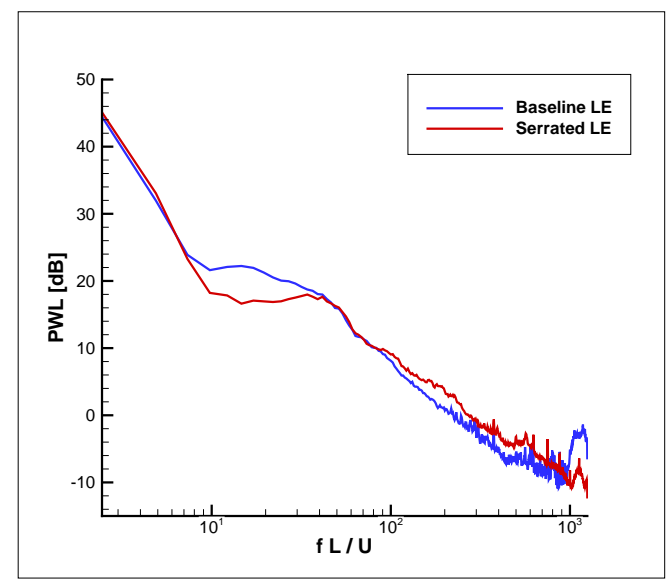

(a) $20 \mathrm{~m} / \mathrm{s}$

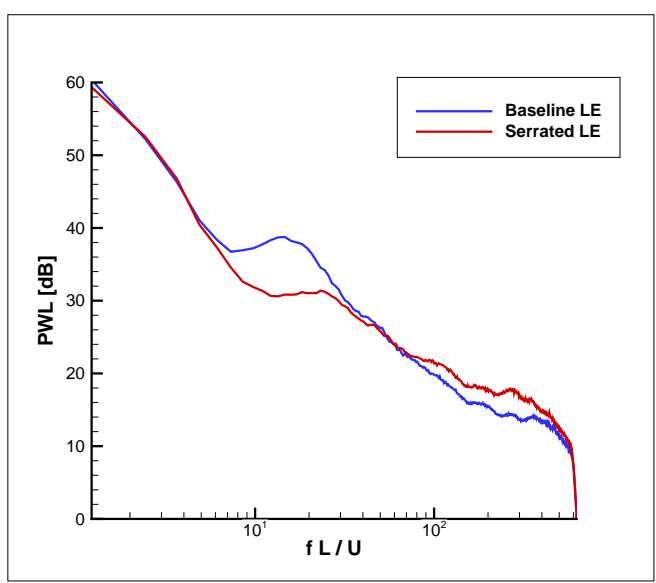

(b) $40 \mathrm{~m} / \mathrm{s}$

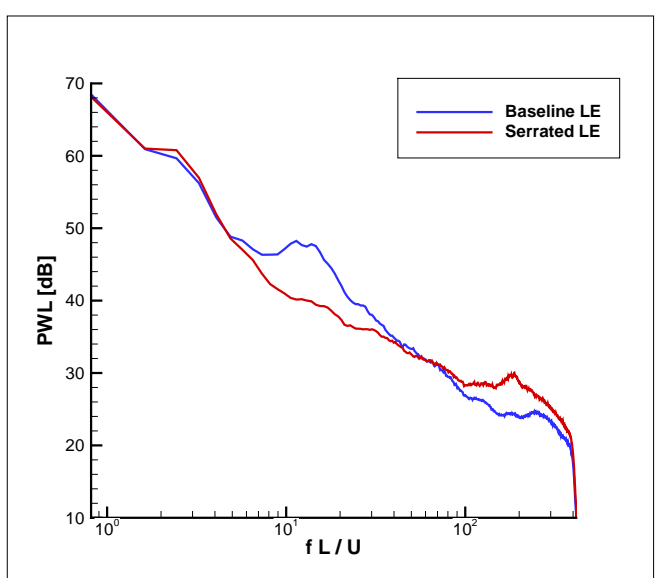

(c) $60 \mathrm{~m} / \mathrm{s}$

Figure 6: Sound Power Levels at 0 degrees AoA and different velocities

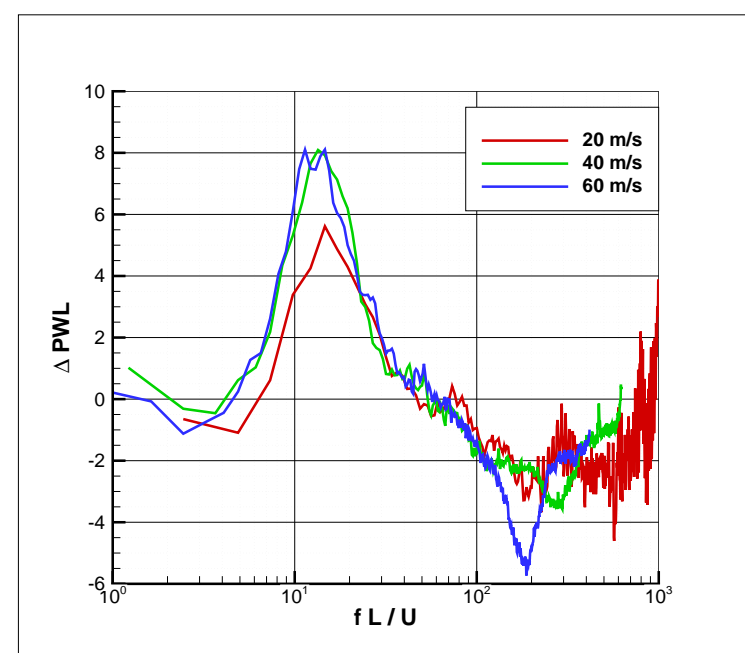

(a) $\triangle P W L$ vs velocity

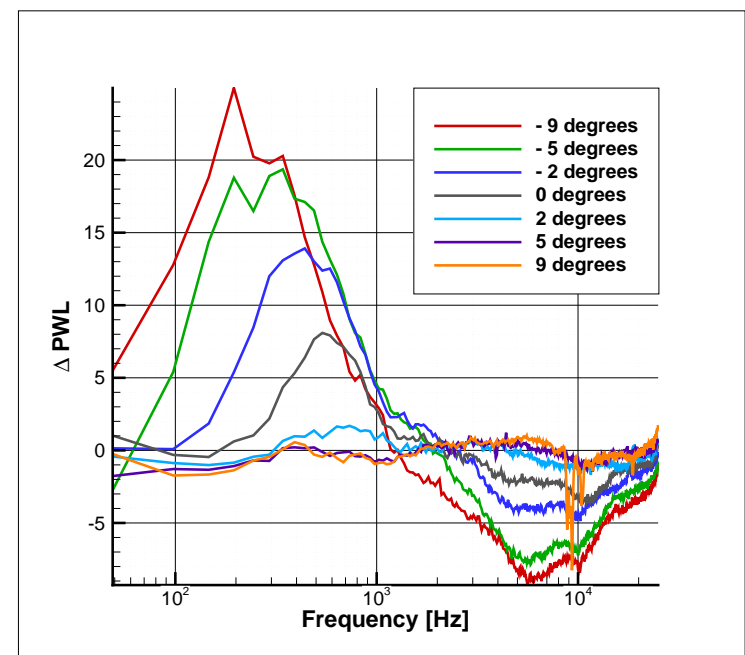

(b) $\triangle P W L$ vs angles

Figure 7: Sound Power Reductions $(\triangle P W L)$ at different velocities (Left) and different angles (Right) 


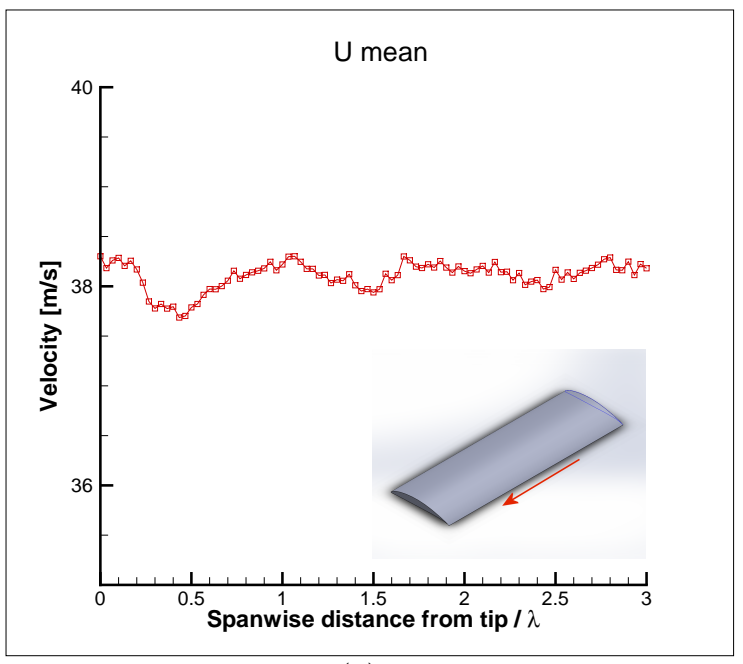

(a) Suction side

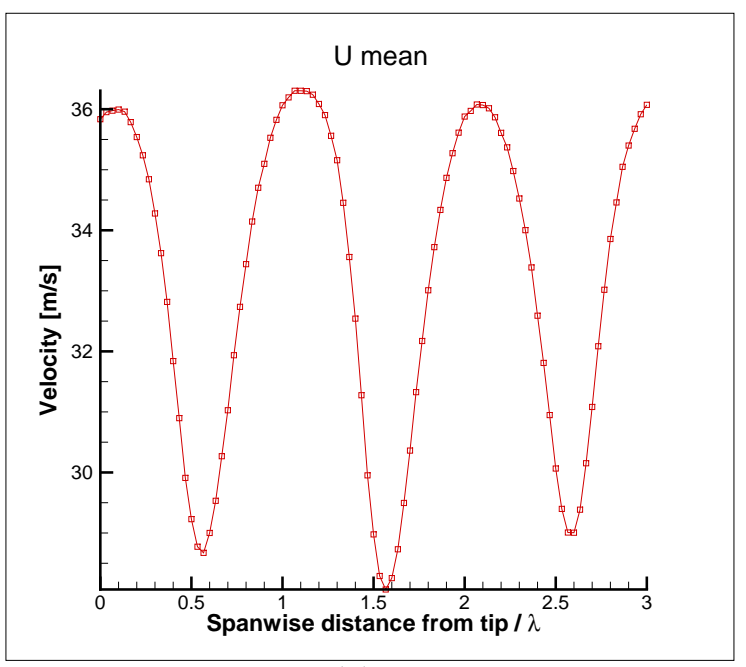

(b) Pressure side

Figure 8: Mean velocity along the streamwise direction

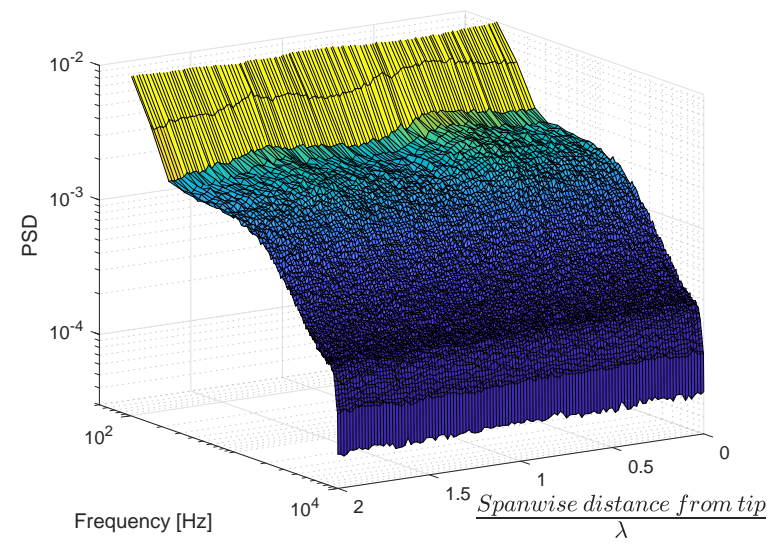

(a) Suction side

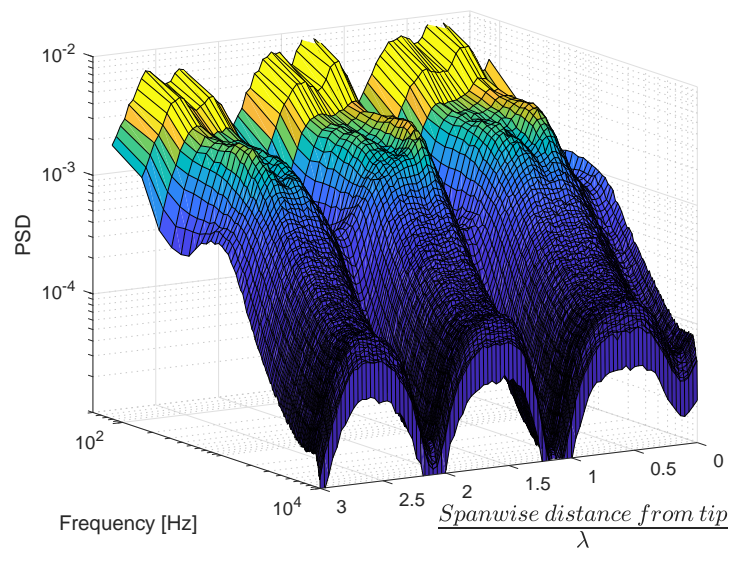

(b) Pressure side

Figure 9: PSD of the streamwise velocity along the spanwise direction of the serrated aerofoil, $40 \mathrm{~m} / \mathrm{s}$

takes place and an increase at high frequencies. So the serrations are able to reduce the power content associated to turbulent fluctuations in that range of frequency.

The subsequent step has been to investigate whether the LE serrations were also modifying the wake profiles. To do so, the vertical profiles of the streamwise velocity are acquired $1 \mathrm{~mm}$ downstream to the TE of the aerofoil at 4 different sites located in correspondence to the tip and the root and the intermediate positions (halfway between tip and root: Mid TR; halfway between root and tip: Mid RT) along two serration wavelengths and compared to the wake profile of the baseline aerofoil.

As can be observed in figure 11, the effect of the serrations is evident more on the pressure side, where the boundary layer at the TE is modified as a function of the position along the serration wavelength, unveiling the existence of some vortical structures centred around the location downstream to the serration root.

\section{Surface pressure direct measurement}

As mentioned before, the aerofoil was instrumented with pressure taps close to the Trailing Edge. Three of them were located on the suction side, directly downstream to the LE serration root and then spaced out along the spanwise direction by $5 \mathrm{~mm}$; Three more were arranged on the pressure side, starting from 


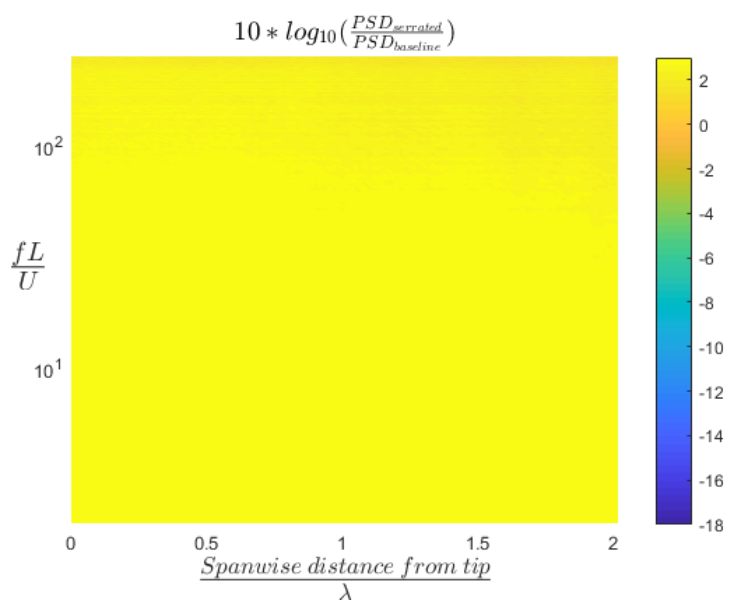

(a) Suction side

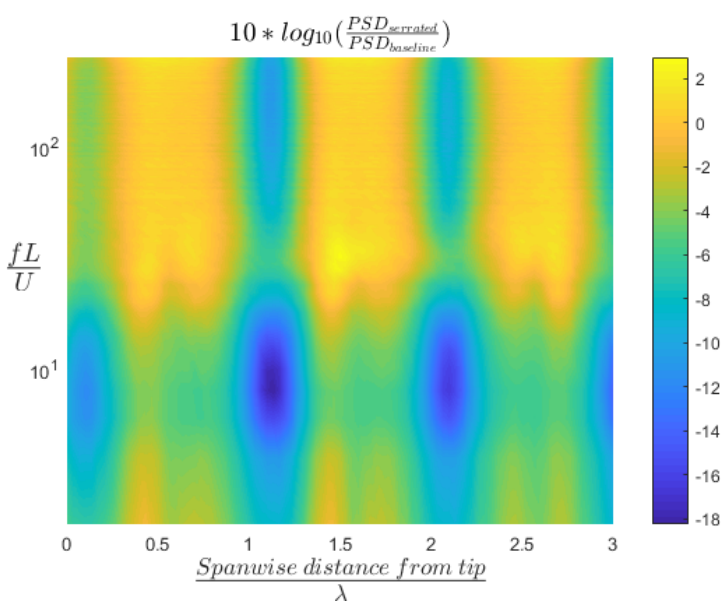

(b) Pressure side

Figure 10: PSD of the streamwise velocity along the spanwise direction of the serrated aerofoil normalized by the baseline PSD, $40 \mathrm{~m} / \mathrm{s}$

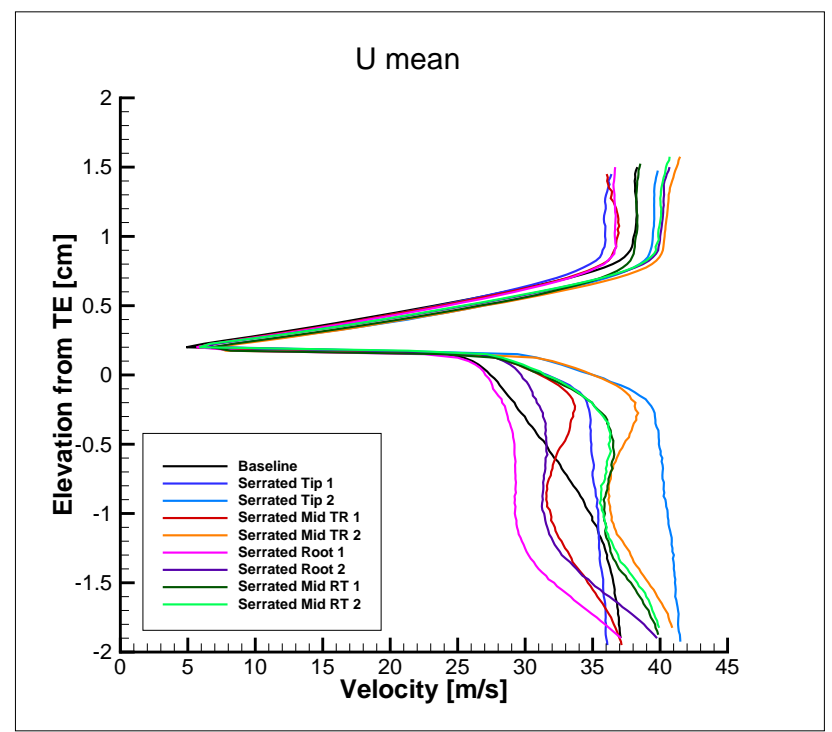

Figure 11: Wake profiles $1 \mathrm{~mm}$ downstream to the TE for the serrated and the baseline aerofoil

the position downstream to the serration tip and then again spaced out along the spanwise direction by 5 $\mathrm{mm}$. It was therefore possible to investigate the modification on surface pressure at the TE induced by LE serrations as compared to the baseline profile.

Figures 12 - 14 show the comparison between the surface pressure spectra in correspondence to three different geometrical angles of attack $(+5 ; 0 ;-5)$ degrees.

From these figures it is evident that the surface pressure on the baseline and serrated aerofoil is equivalent at positive geometrical angles of attack, where no noise reduction occurs, while some differences arise approaching the null and become evident moving to negative geometrical angles of attack. It needs to be stressed out that surface pressure spectra on the serrated aerofoil are not influenced by the angle of attack. Therefore it emerges that the serrations are able to dampen the effect played by the angle of attack on the surface pressure at the TE. 

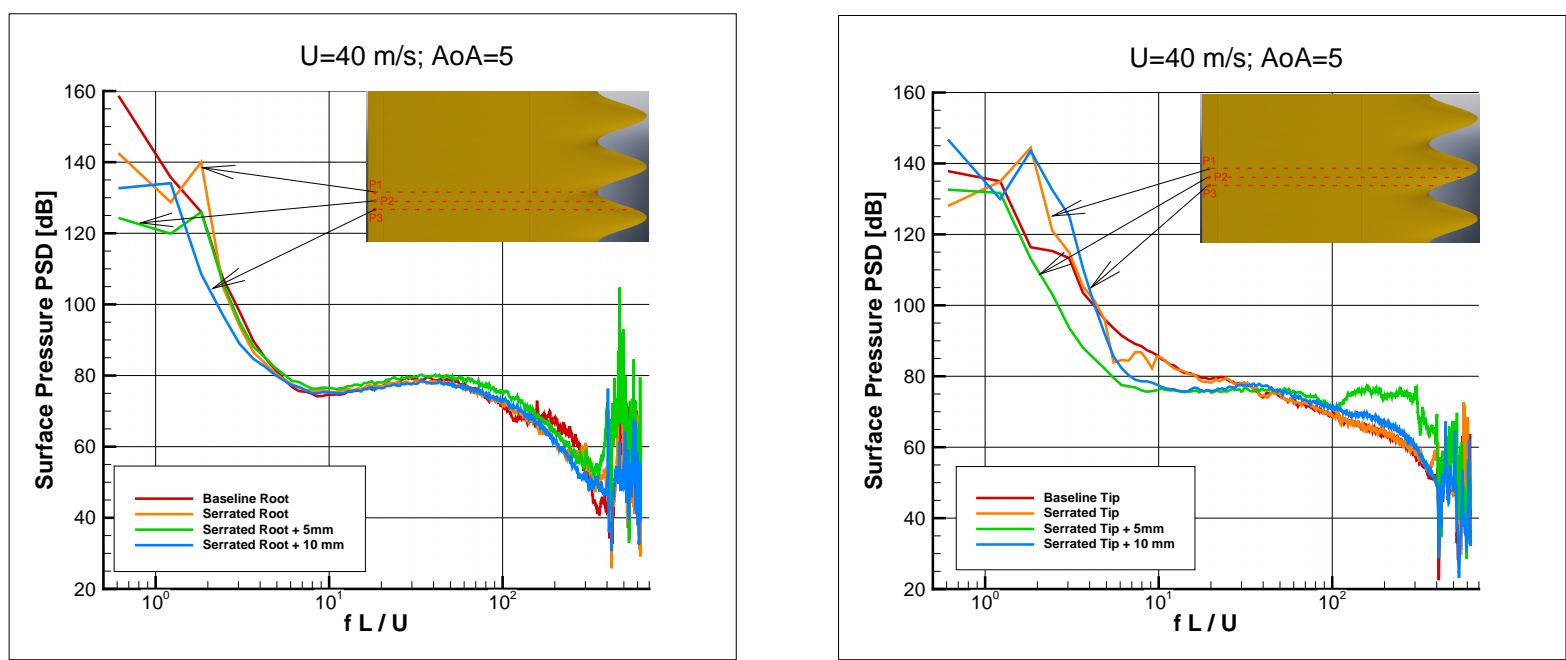

Figure 12: Surface pressure spectrum at the suction (left) and pressure (right) sides of the aerofoil at 5 deg AoA
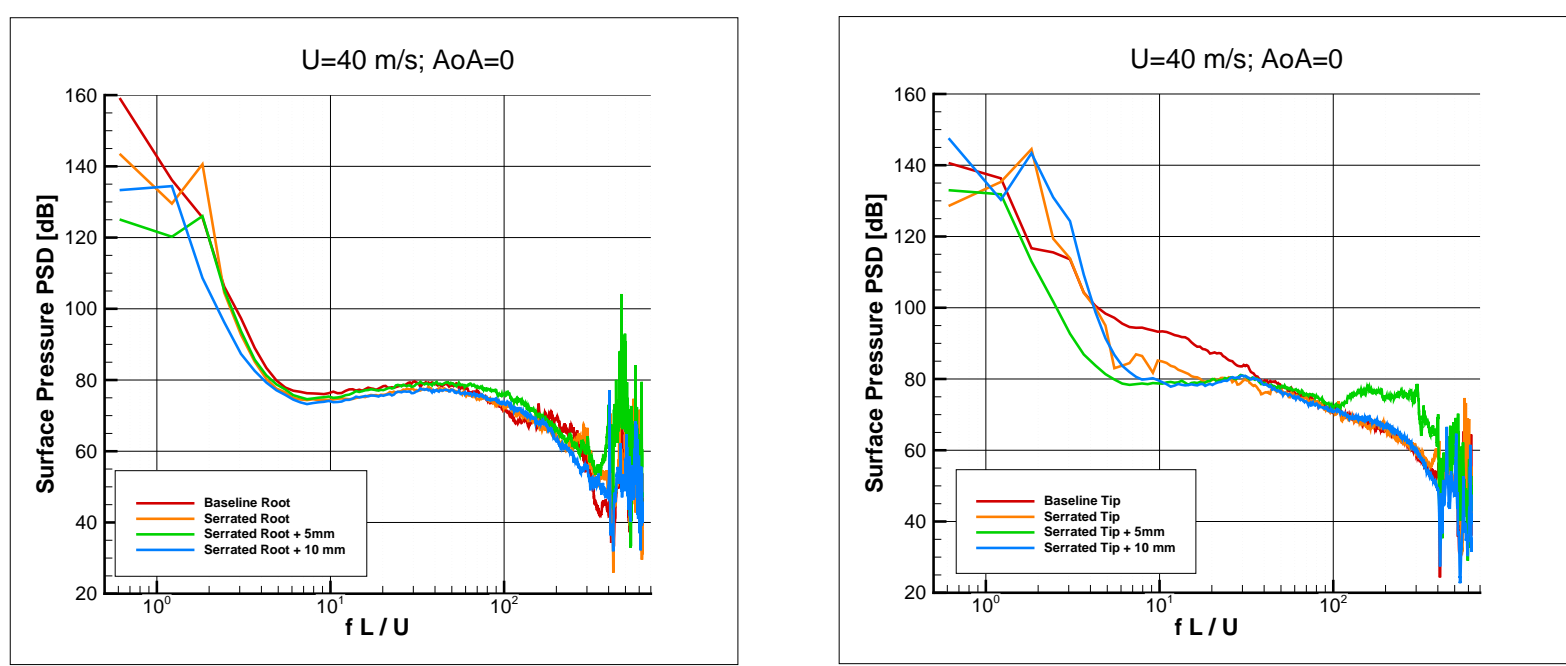

Figure 13: Surface pressure spectrum at the suction (left) and pressure (right) sides of the aerofoil at 0 deg AoA

\section{Coherence}

In order to understand in a greater detail the flow behaviour close to the Trailing Edge, the spectral coherence function has been applied to the signal extracted from different pressure taps locations, displaced of $5 \mathrm{~mm}$ and $10 \mathrm{~mm}$ along the spanwise direction.

As can be seen from figures 15 - 17, no modification arises at positive geometrical AoA while at null and negative AoA the serration are able to reduce the coherence in correspondence to the same range of frequencies where the noise reduction occurs, both at pressure and suction side.

\section{E. Turbulent structure size}

In order to assess the size of the turbulent structures passing over the TE that are responsible of the aerofoil selfnoise, the autocorrelation of the surface pressure signal has been evaluated. Figure 18, where the autocorrelation has been plotted against the space lag of correlation (time lag * U) normalized by the boundary layer $\delta_{99}$ thickness. They show that at positive geometrical angles of attack the size, estimated as the autocorrelation width at $R_{x x}=0.5$, is unchanged. At zero AoA the serrated aerofoil seems to superimpose 

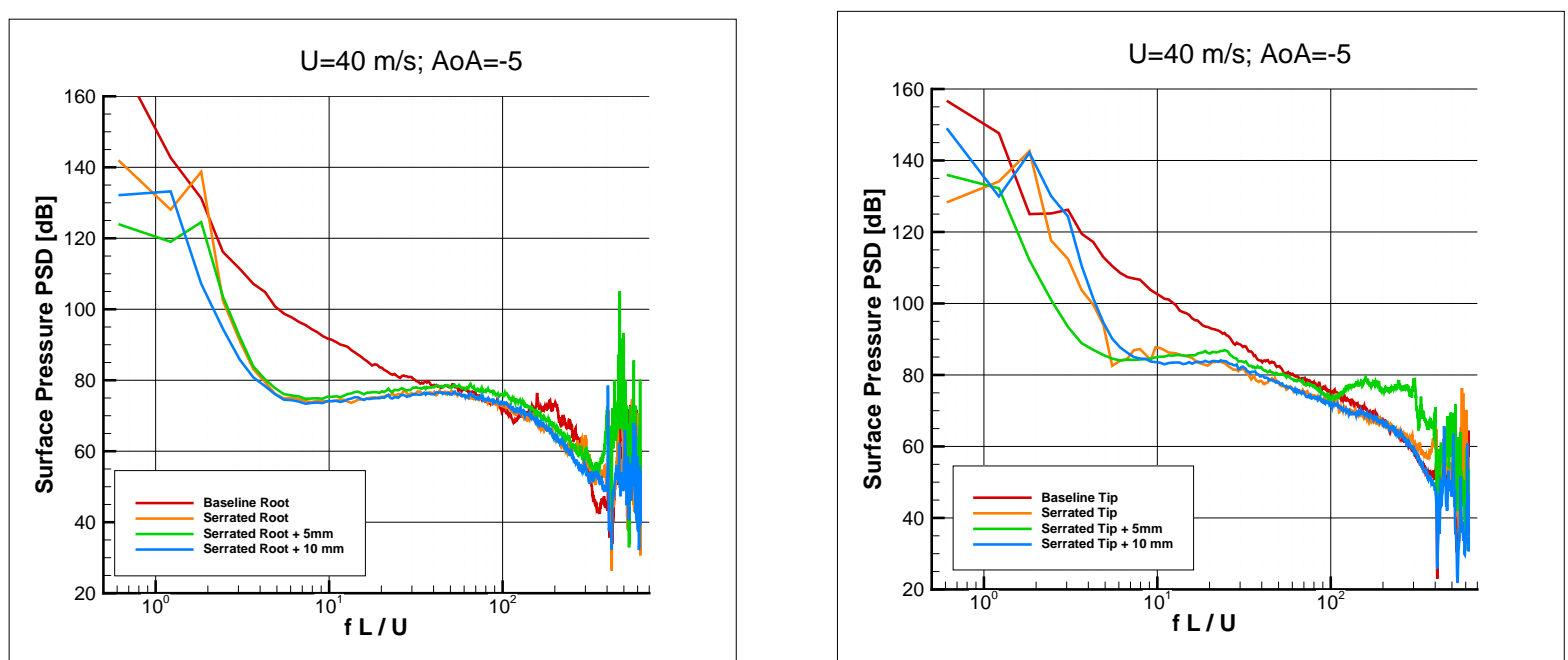

Figure 14: Surface pressure spectrum at the suction (left) and pressure (right) sides of the aerofoil at -5 deg AoA
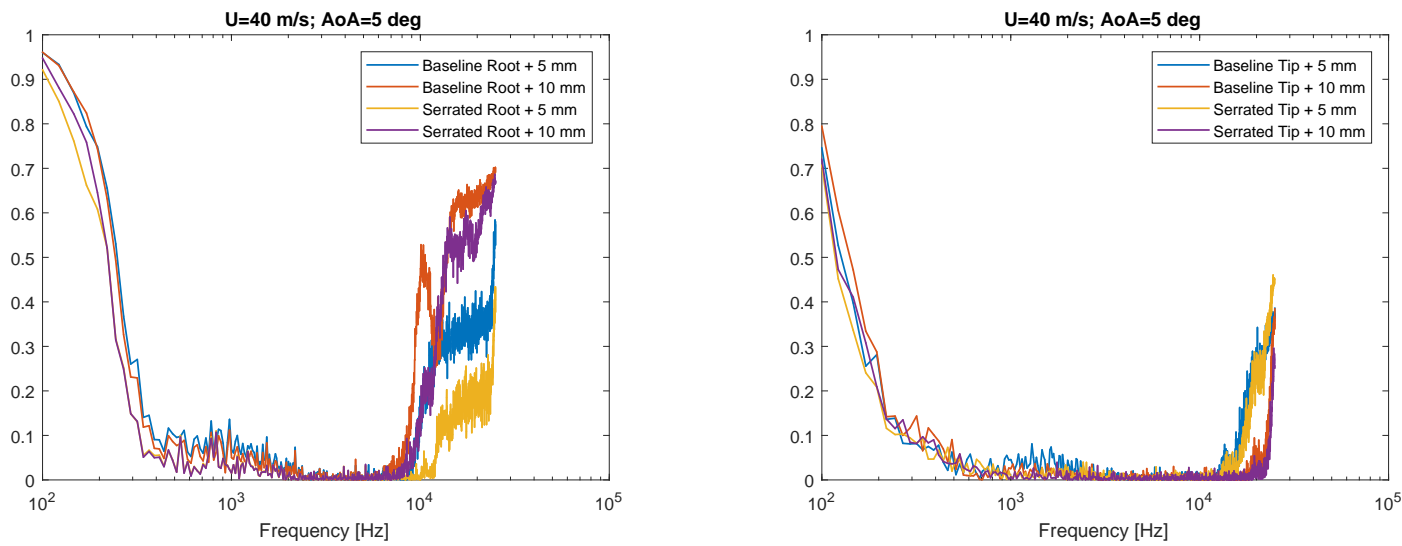

Figure 15: Coherence of the pressure signal between different pressure taps at the suction (left) and pressure (right) sides of the aerofoil at $5 \operatorname{deg}$ AoA
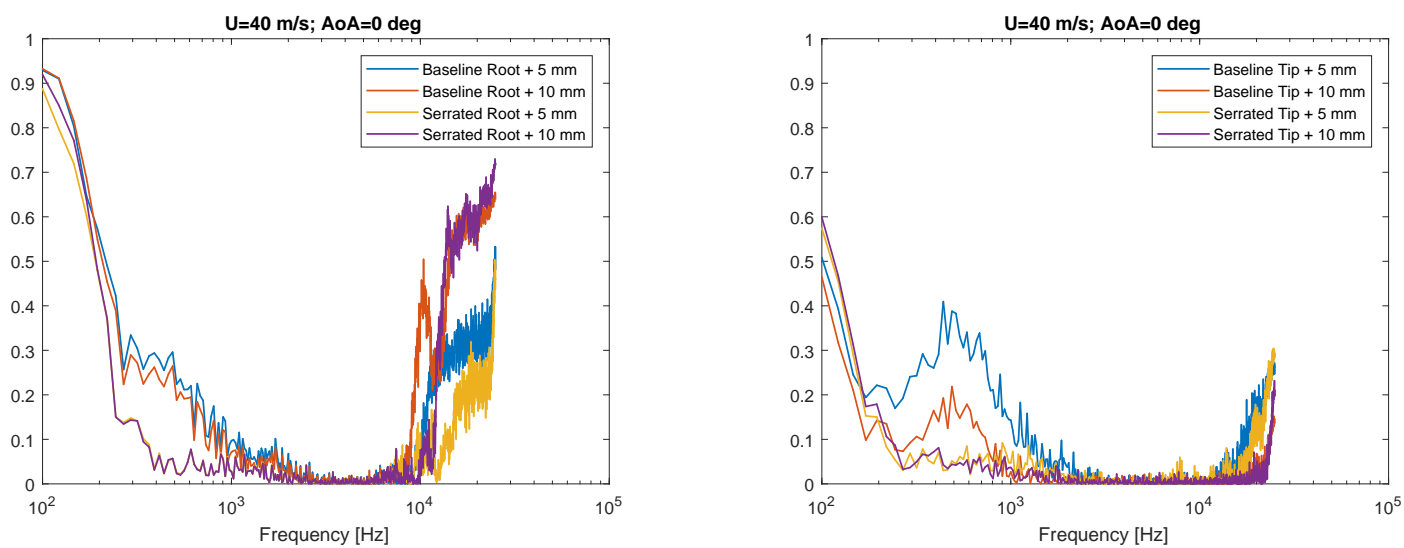

Figure 16: Coherence of the pressure signal between different pressure taps at the suction (left) and pressure (right) sides of the aerofoil at $0 \mathrm{deg}$ AoA 

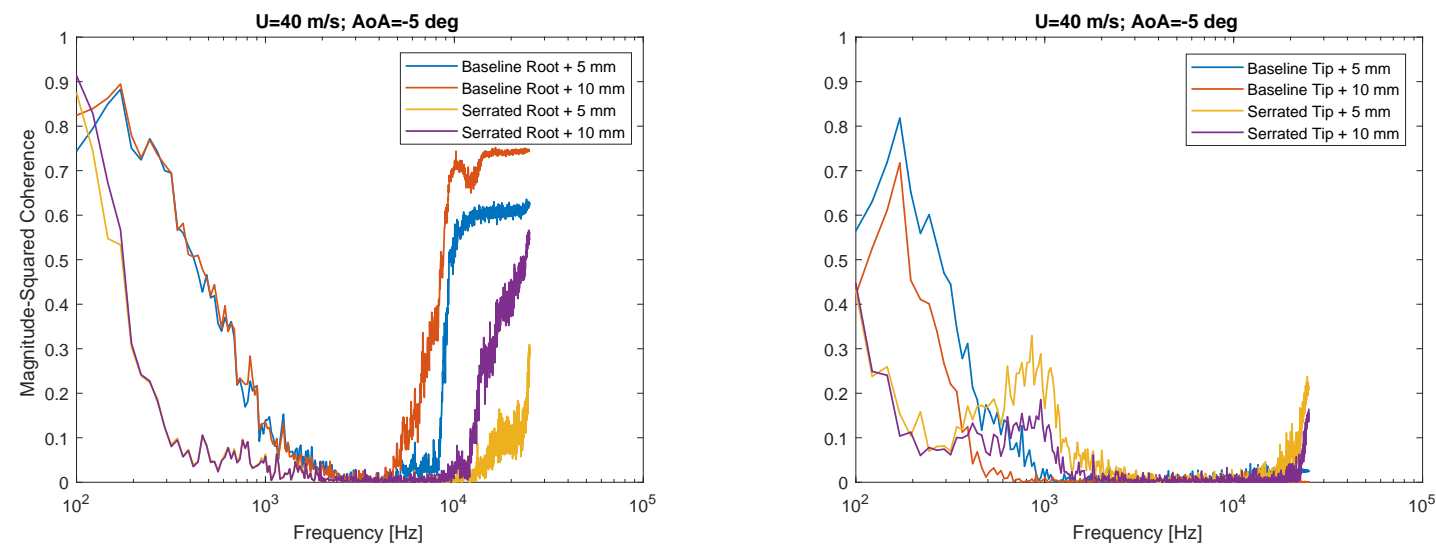

Figure 17: Coherence of the pressure signal between different pressure taps at the suction (left) and pressure (right) sides of the aerofoil at -5 deg AoA

the structures of the baseline a second family of structures of bigger dimension, while at negative angles of attack the serrated aerofoil has turbulent structures smaller than the baseline one. The size of all this turbulent structures is one order of magnitude bigger than the boundary layer thickness. The significance of this result remain still to be partially understood.

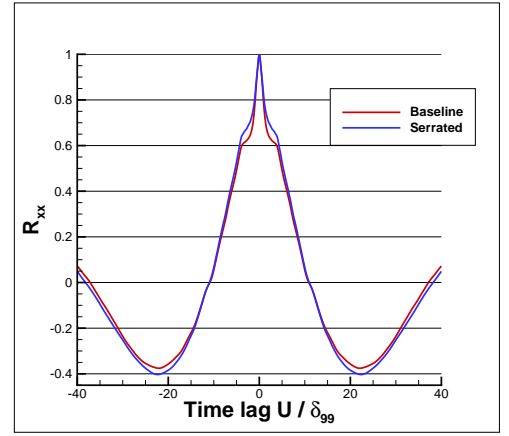

(a) 5 degrees

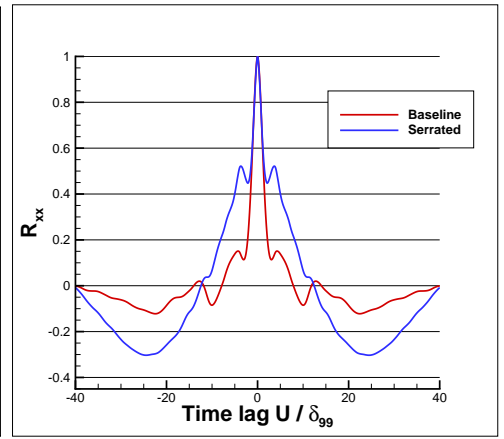

(b) 0 degree

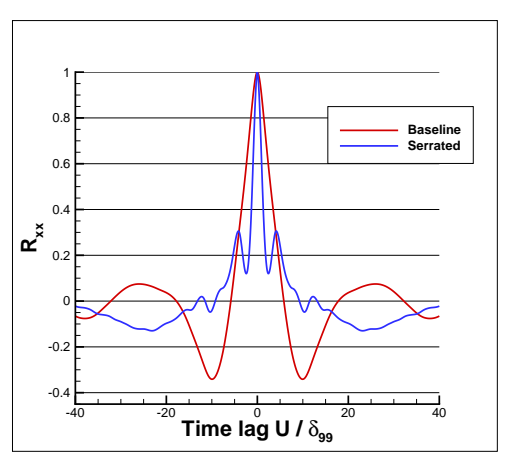

(c) -5 degrees

Figure 18: Autocorrelation of surface pressure signal

\begin{tabular}{ccc}
\hline AoA & Baseline aerofoil & Serrated aerofoil \\
\hline 5 & 0.0509 & 0.0476 \\
0 & 0.0195 & 0.0409 \\
-5 & 0.0299 & 0.0220
\end{tabular}

Table 1: Integral length scale $[\mathrm{m}]$

\section{F. Relation between far field noise and near field pressure}

According to Amiet, ${ }^{14}$ for Trailing Edge noise there exists a proportionality between the far field sound spectrum $S_{p p}$ and the surface pressure spectrum $S_{q q}$. Therefore the ratio between these two quantities in the current measurement has been evaluated in order to assess whether the noise measured in the far field is originated by the surface pressure field at the Trailing Edge. As can be observed in figure 19, this ratio is fairly constant at different angles of attack and along all the investigated frequencies, stating that what is being reduced by the LE serrations is Trailing Edge noise. 


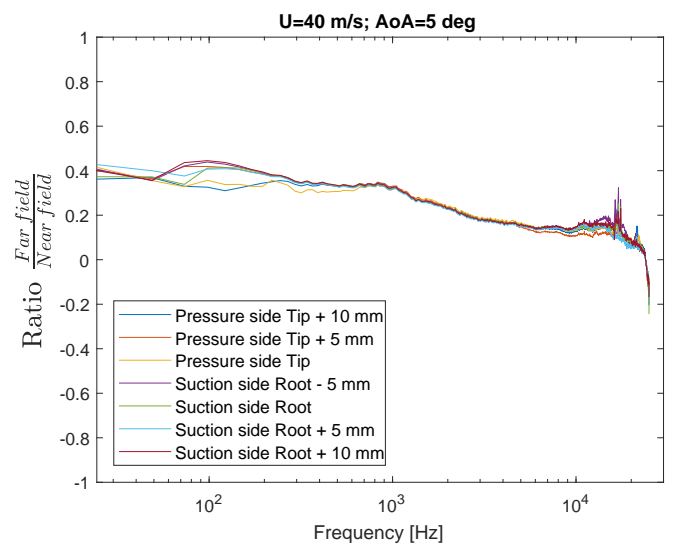

(a) 5 degrees

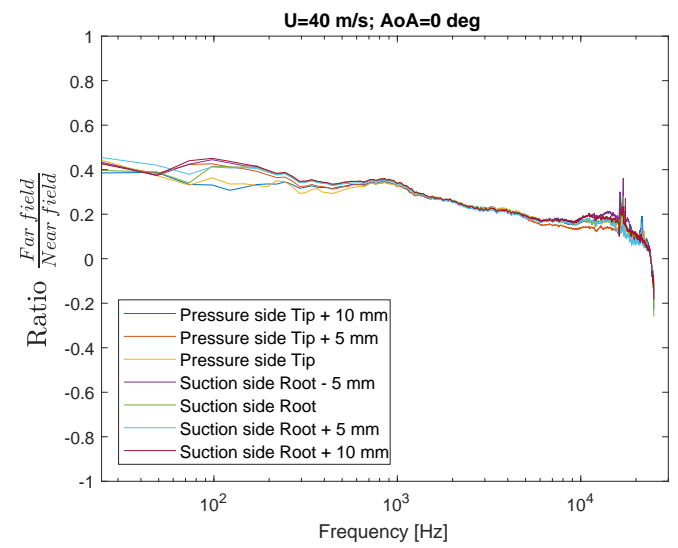

(b) 0 degree

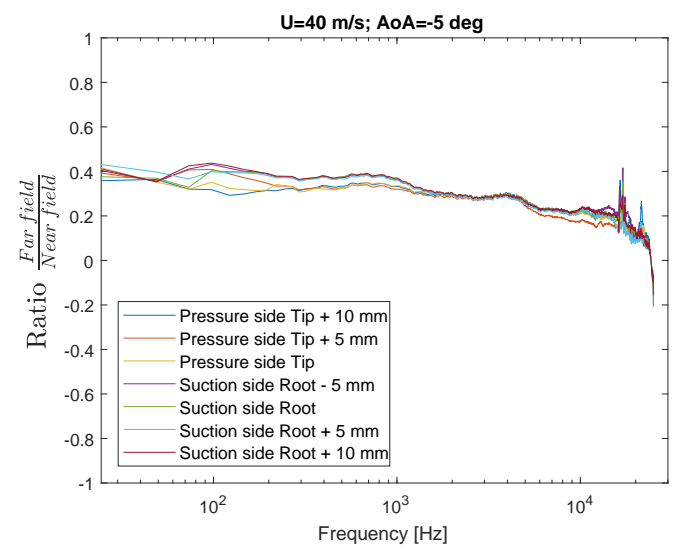

(c) -5 degrees

Figure 19: Ratio between far field noise and near field surface pressure

\section{G. Effect of serration geometry}

Finally five different serration geometries have been compared to assess the effect of the wavelength $\lambda$ and the height $h$ on the self-noise reduction, selecting three different cases for each parameter, see table 2 .

\begin{tabular}{lcc}
\hline Cases & Wavelength $\lambda[\mathbf{m m}]$ & Height $\mathbf{h}[\mathbf{m m}]$ \\
\hline Case 1 & 10 & 10 \\
Case 2 & 10 & 15 \\
Case 3 & 10 & 25 \\
Case 4 & 20 & 25 \\
Case 5 & 30 & 25
\end{tabular}

Table 2: Tested Leading Edge serrations

Figure 20 shows that the serrations wavelength $\lambda$ has a big effect on self-noise reductions, with larger self-noise reductions associated with smaller wavelengths. However, noise reductions must eventually reach a maximum at an optimum wavelength and then reduce until cancelling for configurations close to the baseline.

On the other hand, even though only 3 heights $h$ have been investigated, it appears that there is a maximum serration height above which no further reductions are possible, as depicted in figure 21 


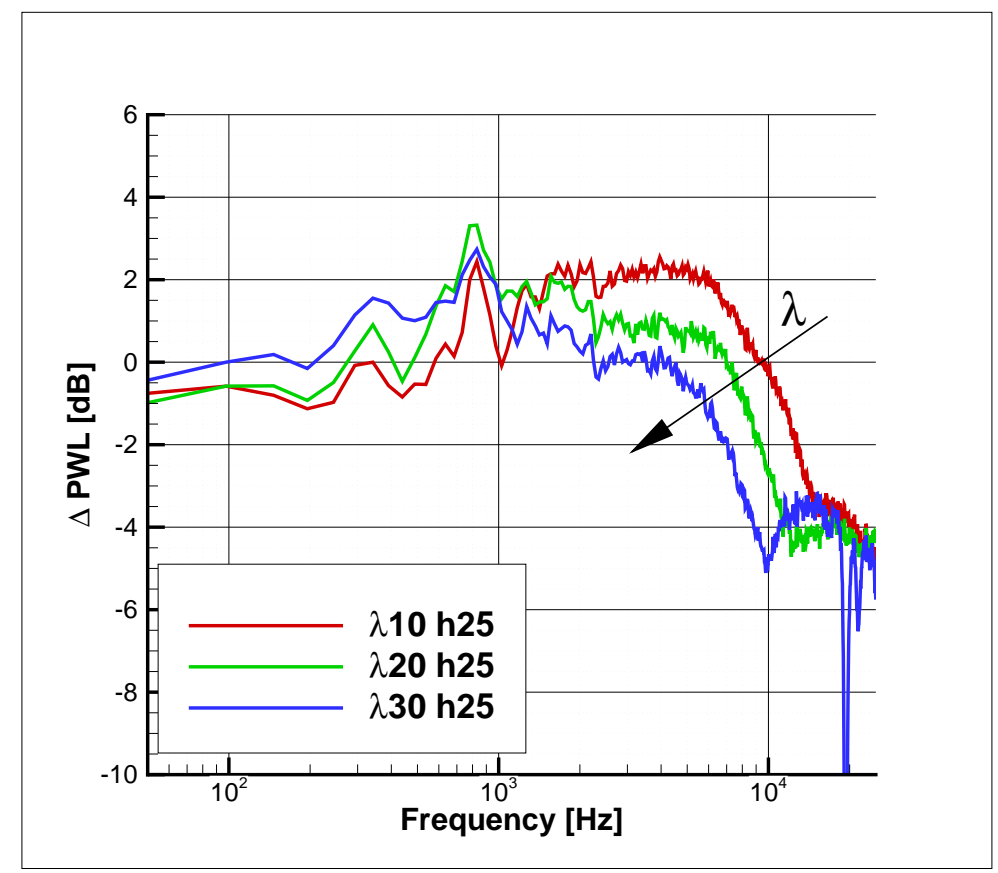

Figure 20: Influence of serrations wavelength $\lambda$ on the self-noise reduction, $60 \mathrm{~m} / \mathrm{s}$

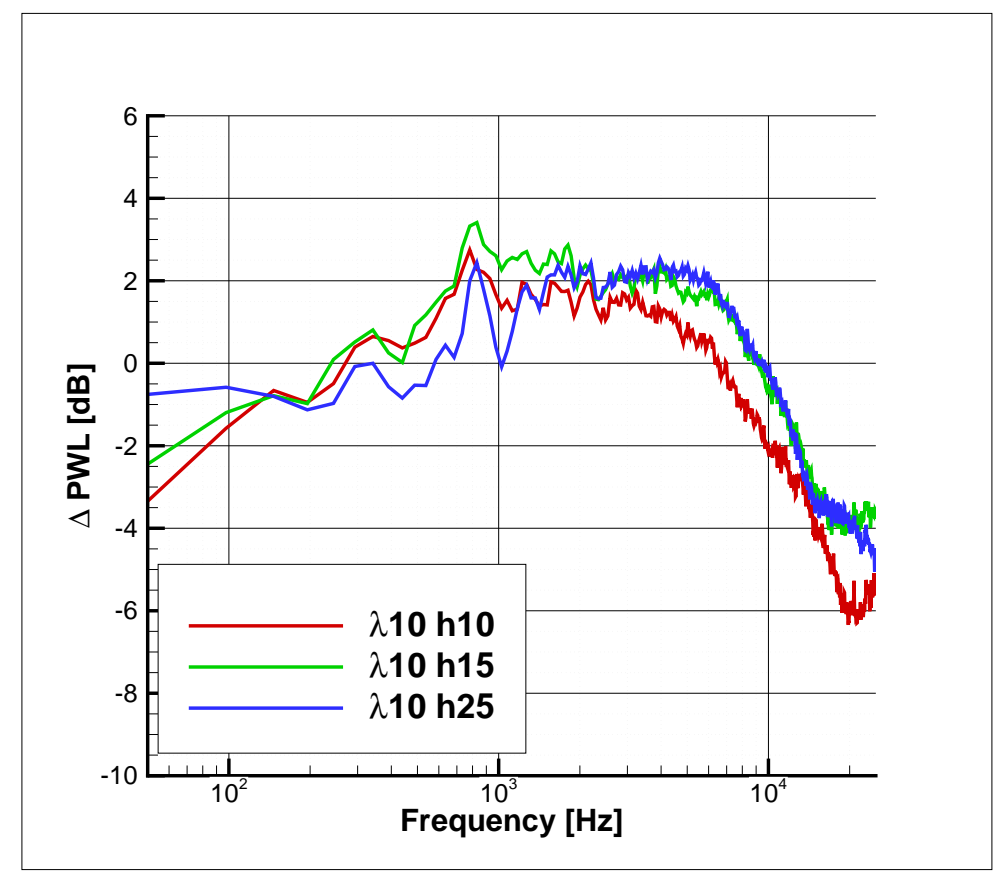

Figure 21: Influence of serrations height $h$ on the self-noise reduction, $60 \mathrm{~m} / \mathrm{s}$

\section{Conclusion}

In this paper leading edge serrations have been shown to be highly effective in reducing aerofoil noise. Noise reductions of up to $20 \mathrm{~dB}$ have been measured at large negative angles of attack and between $5 \mathrm{~dB}$ and $8 \mathrm{~dB}$ at zero geometrical angle of attack. Most likely the noise on the NACA65 aerofoil is the result of separated flow on the pressure side, which is strongest at large negative angles of attack.

The nature of this separation is currently unclear although there is evidence of a small separation bubble 
close to the leading edge at small angles of attack. However, we have demonstrated that it is a form of aerofoil self-noise since reductions in the far field acoustic pressure are associated with an identical reduction in the surface pressure spectrum measured close to the trailing edge.

Leading edge serrations have been shown to produce a significant modulation of the mean velocity (10\%) and turbulent velocity spectrum $(15 \mathrm{~dB})$ on the pressure side close to the trailing edge at frequencies in the low values range of the noise reductions.

Leading edge serrations have been shown to cause a significant reduction in the coherence in the surface pressure between two spanwise positions close to the trailing edge. This suggests that larger scale fluctuations present in the baseline geometry are now absent when leading serrations are introduced. This may suggests that large vertical structures are broken down by the serrations leading to reductions in far field noise.

Small serration wavelengths have been shown to provide larger noise reductions than large wavelength serrations. The reason for this is unclear although it may be associated with the generation of smaller vortical structures generated by the serrations.

Preliminary results suggest that there exists a maximum serration height above which no further noise reductions are possible.

Further investigations are needed to better understand the mechanisms behind this reduction, identifying exactly the source and how this finding can be generalized to different families of aerofoil geometries.

\section{Acknowledgments}

This work was partly supported by EPSRC at the University of Southampton.

\section{References}

\footnotetext{
${ }^{1}$ Alexander Wolf, Thorsten Lutz, Werner Würz, Ewald Krämer, Oksana Stalnov, and Avraham Seifert. Trailing edge noise reduction of wind turbine blades by active flow control. Wind Energy, 18(5):909-923, 2015.

${ }^{2}$ Florence Hutcheson and Daniel Stead. PIV measurements on a blowing flap. In 43rd AIAA Aerospace Sciences Meeting and Exhibit, page 212, 2005.

${ }^{3}$ Jung Hoon Kim, Laith Al-Sadawi, Alexandros Vathylakis, and Tze Pei Chong. Trailing edge noise reduction by passive and active flow controls. In 20th AIAA/CEAS Aeroacoustics Conference, page 3300, 2014.

${ }^{4}$ Mathieu Gruber, Phillip Joseph, and Tze Chong. On the mechanisms of serrated airfoil trailing edge noise reduction. In 17th AIAA/CEAS aeroacoustics conference (32nd AIAA aeroacoustics conference), page 2781, 2011.

${ }^{5}$ Danielle J Moreau, Laura A Brooks, and Con J Doolan. Flat plate self-noise reduction at low-to-moderate reynolds number with trailing edge serrations. In Proceedings of ACOUSTICS, pages 2-4, 2011.

${ }^{6}$ Stefan Oerlemans, Murray Fisher, Thierry Maeder, and Klaus Kögler. Reduction of wind turbine noise using optimized airfoils and trailing-edge serrations. AIAA journal, 47(6):1470-1481, 2009.

${ }^{7}$ Thomas Geyer, Ennes Sarradj, and Christoph Fritzsche. Measurement of the noise generation at the trailing edge of porous airfoils. Experiments in Fluids, 48(2):291-308, 2010.

${ }^{8}$ Michaela Herr. Design criteria for low-noise trailing-edges. In 13th AIAA/CEAS Aeroacoustics Conference (28th AIAA Aeroacoustics Conference), page 3470, 2007.

${ }^{9}$ Arthur Finez, Marc Jacob, Emmanuel Jondeau, and Michel Roger. Broadband noise reduction with trailing edge brushes. In 16th AIAA/CEAS Aeroacoustics Conference, page 3980, 2010.

${ }^{10} \mathrm{P}$ Chaitanya, Phillip Joseph, Subramanyam Narayanan, Christina Vanderwel, Jacob Turner, Jae-Wook Kim, and Bharath Ganapathisubramani. Performance and mechanism of sinusoidal leading edge serrations for the reduction of turbulence-aerofoil interaction noise. Journal of Fluid Mechanics, 818:435-464, 2017.

${ }^{11}$ Mathieu Gruber. Airfoil noise reduction by edge treatments. 2012.

${ }^{12}$ Thomas F Brooks, D Stuart Pope, and Michael A Marcolini. Airfoil self-noise and prediction. 1989.

${ }^{13}$ TP Chong, PF Joseph, and POAL Davies. Design and performance of an open jet wind tunnel for aero-acoustic measurement. Applied acoustics, 70(4):605-614, 2009.

${ }^{14} \mathrm{RK}$ Amiet. Noise due to turbulent flow past a trailing edge. Journal of sound and vibration, 47(3):387-393, 1976.

${ }^{15}$ Giovanni Paolo Romano. Analysis of two-point velocity measurements in near-wall flows. Experiments in fluids, 20(2):6883, 1995.

${ }^{16}$ Chaitanya Paruchuri, Narayanan Subramanian, Phillip Joseph, Christina Vanderwel, Jae Wook Kim, and Bharathram Ganapathisubramani. Broadband noise reduction through leading edge serrations on realistic aerofoils. In 21st AIAA/CEAS Aeroacoustics Conference, page 2202, 2015.
} 